\title{
Can oil, plastic and RAP wastes have a new life in novel asphalt mixtures?
}

\author{
S. Fernandes, L. Costa, H. Silva \& J. Oliveira \\ CTAC - Territory, Environment and Construction Centre, University of Minho, Guimarães, Portugal
}

A. Machado \& F. Duarte

IPC/I3N - Institute of Polymers and Composites, University of Minho, Guimarães, Portugal

\begin{abstract}
The pavement recycling allows to reuse reclaimed asphalt pavement (RAP) or other waste materials in new asphalt mixtures for road construction or rehabilitation, thus reducing the use of virgin materials (aggregates and bitumen). Thus, the main aim of this study is to minimize the use of natural resources through the reuse of three waste materials: HDPE, motor oil and RAP. Different amounts of waste motor oil and HDPE were added to an asphalt binder with $50 \%$ aged bitumen. The best solutions to produce the modified binders (4.5 to $5.0 \%$ HDPE and $10 \%$ waste motor oil) performed as well as a conventional bitumen although they only used $35 \%$ of virgin bitumen. Asphalt mixtures with $50 \%$ RAP were produced with the selected modified binders, improving some characteristics in comparison with conventional asphalt mixtures. In conclusion, these wastes can revive in new asphalt mixtures.
\end{abstract}

\section{INTRODUCTION}

The pavement recycling presents environmental and economic advantages for the paving Industry. From an environmental point of view, the pavement recycling enables to reduce the amount of new aggregates and bitumen used, the disposal area required for placing milled material and the energy consumption. Besides the environmental advantages, the pavement recycling can present economic benefits in comparison to the traditional pavement overlay and it can solve other problems, such as cracking, roughness and/or others pathologies (INIR, 2012).

According to data provided by EAPA (2011), 2000 tonnes of reclaimed asphalt were available in Portugal, in 2011, of which $60 \%$ were used in hot and warm recycling, $5 \%$ in cold recycling and $15 \%$ in unbound layers. However, the recycling rates in some European countries is very low although considerable amounts of reclaimed asphalt are available (EAPA, 2012).Thus, it is observed that asphalt recycling techniques are still poorly used in Europe.

Reclaimed asphalt pavement (RAP) used in asphalt recycling is a heterogeneous material (Karlsson \& Isacsson, 2006), since it depends on the amount and type of materials used in the initial road construction, in the maintenance or conservation history of the pavement and in the RAP transportation and storing conditions (Vislavičius \& Sivilevičius, 2013). RAP is a difficult material to characterize, which requires a high experience and knowledge when it is used in new asphalt mixtures comparatively to the conventional ones (Karlsson \& Isacsson, 2006).

Several authors (Sengoz \& Oylumluoglu, 2013, Reyes-Ortiz et al., 2012) studied and evaluated the use of different amounts of RAP in new recycled asphalt mixtures and their mechanical performance. The reclaimed asphalt pavement already contains bitumen, but due to its short-term and long-term aging it is necessary to add a recycling agent (Karlsson \& Isacsson, 2006). The recycling agent or rejuvenator should change the aged binder in order to give it typical mechanical proprieties of a conventional bitumen (Dony et al., 2013). Some examples of rejuvenators are soft grade bitumens, vegetal oil (Dony et al., 2013), extender oils (Karlsson \& Isacsson, 2006) and waste motor oil (Silva et al., 2012). 
The waste motor oil is a residue used for rejuvenating or preventing the bitumen aging, because it dilutes the asphaltenes from the aged binder by adding maltenes (Lesueur, 2009). The addition of waste motor oil reduces the mixing and compaction temperatures and the bitumen's viscosity (Silva et al., 2012) and its reuse can present benefits at an environmental and economic level. However, the use of high quantities of rejuvenator can cause rutting problems, which can be avoided by using plastic modification. Thus, waste plastic can be used in bitumen modification to improve the pavement performance, namely by decreasing rutting, cracking and thermal susceptibility (Costa et al., 2013). The high density polyethylene (HDPE) is available in large amounts at a low price (Casey et al., 2008), and is one of the waste plastics that can be used for bitumen modification. It decreases the penetration and increases the softening point temperature and the resistance to the variation of temperature (Al-Hadidy \& Yi-qiu, 2009).

Taking this into account, the main objective of this study is to reduce the amount of virgin materials used in new asphalt mixtures, by using 50\% of RAP material and a new modified bitumen that maximizes the use of waste materials (waste motor oil and HDPE).

\section{MATERIALS AND METHODS}

\subsection{Materials}

The materials used in this study were a reclaimed asphalt pavement (RAP), new aggregates, a conventional bitumen and two additives or modifiers (waste motor oil and waste HDPE).

The RAP material was obtained by milling a surface layer of a highway pavement, which was separated in two fractions (fine and coarse) by a classifier with a sieve opening of $8 \mathrm{~mm}$. The aged bitumen recovered from the RAP material is a very hard binder with a penetration of $9 \mathrm{dmm}$ and a softening temperature of $74^{\circ} \mathrm{C}$.

The selected aggregates are crushed rock aggregates of granite origin, except the filler that is of limestone origin. The conventional bitumen from CEPSA has got a penetration of $35 \mathrm{dmm}$ and a softening point of $54{ }^{\circ} \mathrm{C}$. This bitumen was modified with waste motor oil and waste HDPE. Then, it was mixed with aged bitumen from RAP and its characteristics were compared with the initial bitumen. The waste motor oil from heavy vehicles showed a viscosity between 0.1 and 0.005 Pa.s, over the temperature range studied (30 to $\left.180^{\circ} \mathrm{C}\right)$. In turn, the HDPE was supplied with a maximum dimension of $4 \mathrm{~mm}$ and its melting temperature was $134^{\circ} \mathrm{C}$.

\subsection{Methods}

The 35/50 bitumen was modified with the waste polymer (HDPE) in a high shear mixer at $7200 \mathrm{rpm}$, for $20 \mathrm{~min}$, at temperature of $180^{\circ} \mathrm{C}$, in order to obtain a homogeneous modified binder. Then, the necessary amount of waste motor oil was introduced into the modified bitumen by using a low shear mixer, during $10 \mathrm{~min}$, at a temperature of $180^{\circ} \mathrm{C}$. At the end, the bitumen modified with polymer and waste motor oil was added to the aged bitumen in a proportion of $50 \%$, during $2 \mathrm{~min}$, at a temperature of $180^{\circ} \mathrm{C}$. It should be pointed out that some samples were only modified with waste motor oil for comparison reasons.

Initially, binders with different amounts of waste motor oil (10, 15 and $20 \%)$ were studied. These binders were modified with $5 \%$ of HDPE (maximum recommended percentage), and the most promising modified binder allowed to select the amount of waste motor oil to use in the next phase. Then, several percentages of HDPE (namely, 2.5, 3.5 and $4.5 \%$ ) were studied with this amount of waste motor oil. The content of each material and their classification are shown in Table 1.The final modified binders, already mixed with the aged bitumen, were characterized by penetration at $25^{\circ} \mathrm{C}$ (EN 1426), softening point temperature (EN 1427) and dynamic viscosity (EN 13302) tests. Finally, the modified binders (with oil and HDPE) with characteristics similar to those of a conventional 35/50 pen bitumen (base bitumen used in this study) were selected to produce recycled asphalt mixtures in order to evaluate their mechanical performance.

With regards to the production of recycled asphalt mixtures with RAP (AC 14 Surf mixtures with a binder content of $5 \%$ ), the procedure starts with the addition of new aggregates at a temperature of $230{ }^{\circ} \mathrm{C}$ together with $20 \%$ of the coarse RAP fraction. These materials should be mixing during 1 minute, to ensure their homogeneity. After that, $30 \%$ of the fine RAP fraction is introduced at room temperature in the previous mixture, during 2 minutes, in order to 
homogenize the mixture's temperature. Then, the modified bitumen with waste materials (at $180^{\circ} \mathrm{C}$ ) is added to the mixture, during 2 minutes, as recommended in EN 12697-35 standard. This production process is based in a previous study of Palha et al. (2013). All mixtures were tested for water sensitivity (EN 12697-23) and rutting resistance (EN 12697-22) in order to evaluate their performance.

Table 1. Percentage of each waste material used in the studied binders.

\begin{tabular}{lrrrr}
\hline Modified binder & Aged bitumen & Bitumen35/50 & Polymer & Motor oil \\
\hline B10/20 & 100.0 & 0.0 & 0.0 & 0.0 \\
RBO10 & 50.0 & 40.0 & 0.0 & 10.0 \\
RBO15 & 50.0 & 35.0 & 0.0 & 15.0 \\
RBO20 & 50.0 & 30.0 & 0.0 & 20.0 \\
RBP5O10 & 50.0 & 35.0 & 5.0 & 10.0 \\
RBP5O15 & 50.0 & 30.0 & 5.0 & 15.0 \\
RBP5O20 & 50.0 & 25.0 & 5.0 & 20.0 \\
RBP2.5O10 & 50.0 & 37.5 & 2.5 & 10.0 \\
RBP3.5O10 & 50.0 & 36.5 & 3.5 & 10.0 \\
RBP4.5O10 & 50.0 & 35.5 & 4.5 & 10.0 \\
\hline
\end{tabular}

\section{RESULTS}

\subsection{Selection of waste materials contents}

The basic properties of the studied binders are presented in Table 2. The increase of the waste motor oil content increases the penetration values and decreases the softening point temperatures. In turn, the addition of HDPE reduces the penetration values and raises the softening point temperatures. It is possible to verify that only the modified bitumen with $5 \%$ of waste HDPE and $10 \%$ of waste motor oil has penetration values similar to those of a conventional B35/50 bitumen, with the advantage of having a higher softening point temperature value. Thus, the study will proceed only with $10 \%$ of waste motor oil and with a range of HDPE contents in order to find best modified binders that are able to maximize the use of waste materials.

Table 2. Penetration and R\&B test results with different contents of waste motor oil and HDPE.

\begin{tabular}{lrrr}
\hline Binder & Penetration at $25^{\circ} \mathrm{C}$ & & Softening point temperature \\
\cline { 2 - 2 } & $\mathrm{dmm}$ & ${ }^{\circ} \mathrm{C}$ \\
\hline B35/50 & 35 & 54 \\
RBO10 & 77 & 47 \\
RBO15 & 166 & 41 \\
RBO20 & 304 & 34 \\
RBP5O10 & 43 & 81 \\
RBP5O15 & 98 & 52 \\
RBP5O20 & 188 & 47 \\
\hline
\end{tabular}

According to the Figure 1, for the same percentage of waste motor oil, the increase of HDPE content decreases the penetration values and increases the softening point values. It should be pointed out that the softening point values are very similar for HDPE amounts between 2.5 and $4.5 \%$, largely increasing for a HDPE amount of $5 \%$. This sharp variation can be related with a phase change in the binder, when HDPE concentration is enough to create internal structures.

The dynamic viscosity results (Figure 2) confirm the previous observations. The viscosity of the binder modified only with waste motor oil is lowest one, while the other modified binders (with waste motor oil and HDPE) present a viscosity similar or higher than that of the conventional bitumen. Again, the modified bitumen with $5 \%$ of HDPE and $10 \%$ of waste motor oil (RBP5O10) exhibits the highest viscosity, followed by the RBP4.5O10 binder. 


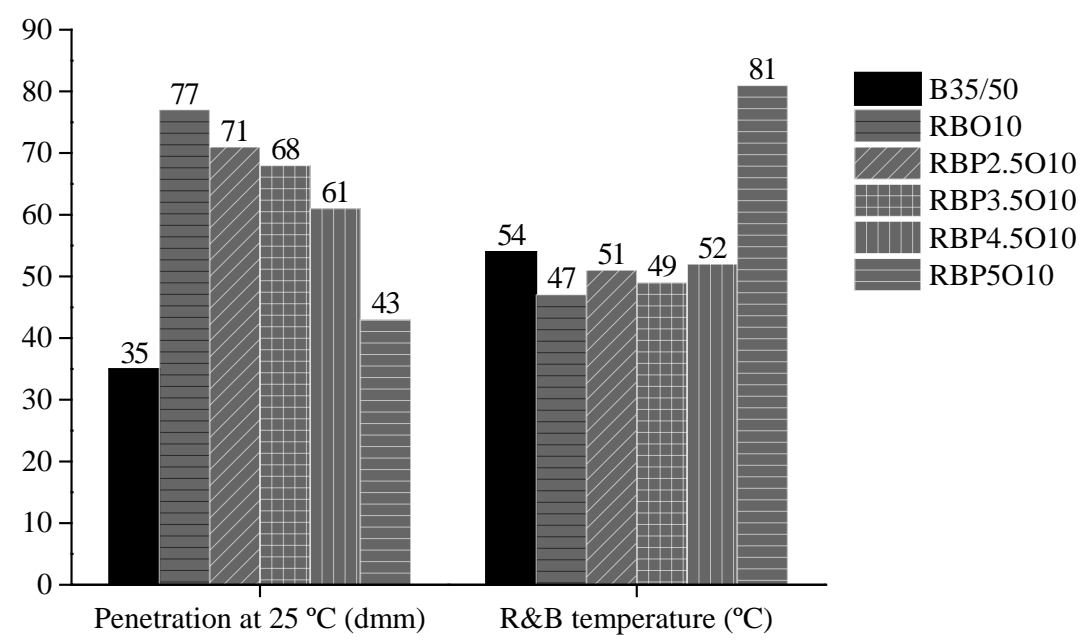

Figure 1. Penetration and softening point test results of binders with different contents of HDPE and $10 \%$ of waste motor oil.

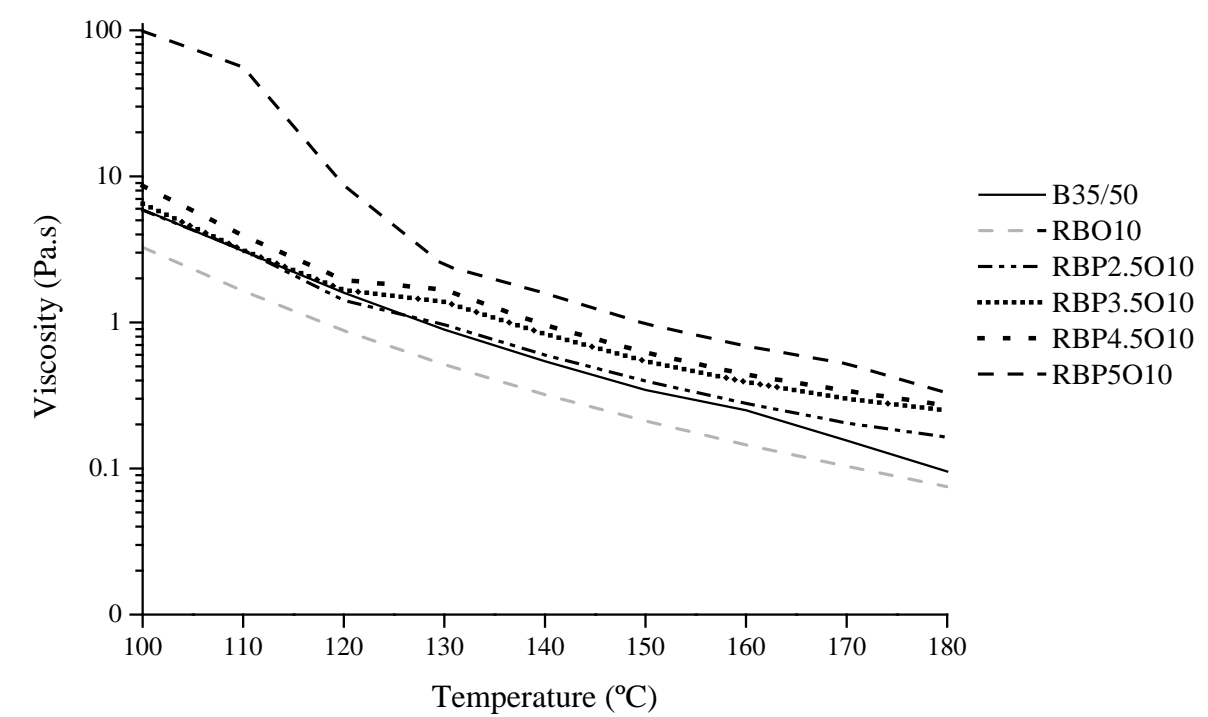

Figure 2. Dynamic viscosity results of binders with different contents of HDPE and $10 \%$ of waste motor oil.

In view of the above results, only one of the modified bitumens, i.e. RBP5O10, showed similar or higher proprieties than those of a conventional B35/50 pen bitumen. However, the modified bitumen RBP4.5O10 presents characteristics similar to those of a conventional B50/70 pen bitumen (also used for road construction), while avoiding some possible problems related with the lower workability of binders with higher viscosity. Thus, these two modified bitumens (RBP5O10 and RBP4.5O10) were selected to produce recycled asphalt mixtures in order to evaluate their performance, which was compared with that of a conventional mixture produced with the base bitumen used in this study (B35/50).

\subsection{Performance of conventional and recycled HMA mixtures}

Figure 3 presents the water sensitivity and the air voids contents results of the studied mixtures determined based on EN 12697-8 standard (method A). The different asphalt mixtures showed similar water sensitivity values that ranged between $66 \%$ and $71 \%$, and among these values the conventional asphalt mixture presented the lowest water sensitivity. With respect to the air voids content, the novel asphalt mixtures with modified binder revealed air voids contents 
slightly higher than those specified for an AC 14 Surf mixture (3\% to $5 \%$ ). Nevertheless, the higher voids contents of these new mixtures should not pose a problem because their water sensitivity was very close to that of the conventional asphalt mixture. The higher air voids contents of these new recycled mixtures could have been caused by the use of RAP material or by the higher viscosity of the binders modified with HDPE at high working temperatures.

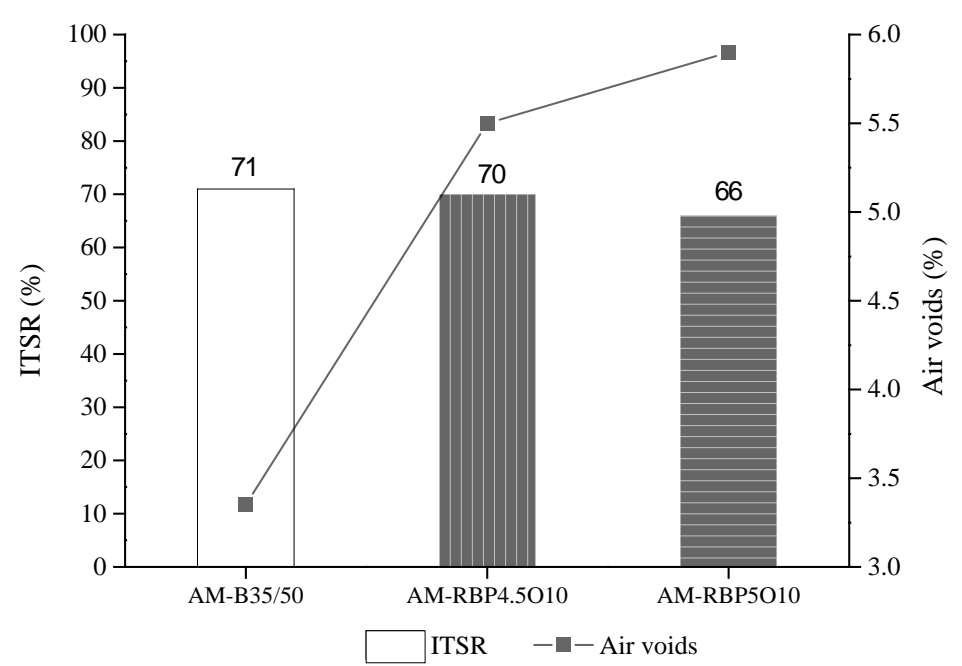

Figure 3. Water sensitivity and air voids results of the studied mixtures.

The resistance to permanent deformation (rutting) was determined through the measurement of the rut depth formed by successive passages of a loading wheel over the tested mixture. The evolution of the rut depth with the number of cycles was used to rank the permanent deformation performance of asphalt mixtures (Figure 4), namely by means of the wheel-tracking slope in air $\left(\mathrm{WTS}_{\mathrm{AIR}}\right)$ parameter. The asphalt mixtures with $4.5 \%$ or $5.0 \%$ of HDPE and $10 \%$ of waste motor oil (AM-RBP4.5O10 and AM-RBP5O10) presented higher rutting resistance in comparison with the conventional mixture (AM-B). Moreover, both asphalt mixtures with the new modified binders presented very low WTS $_{\text {AIR }}$ values, clearly lower than those of the conventional mixture, which is an indicator of the good rutting performance of these new mixtures.

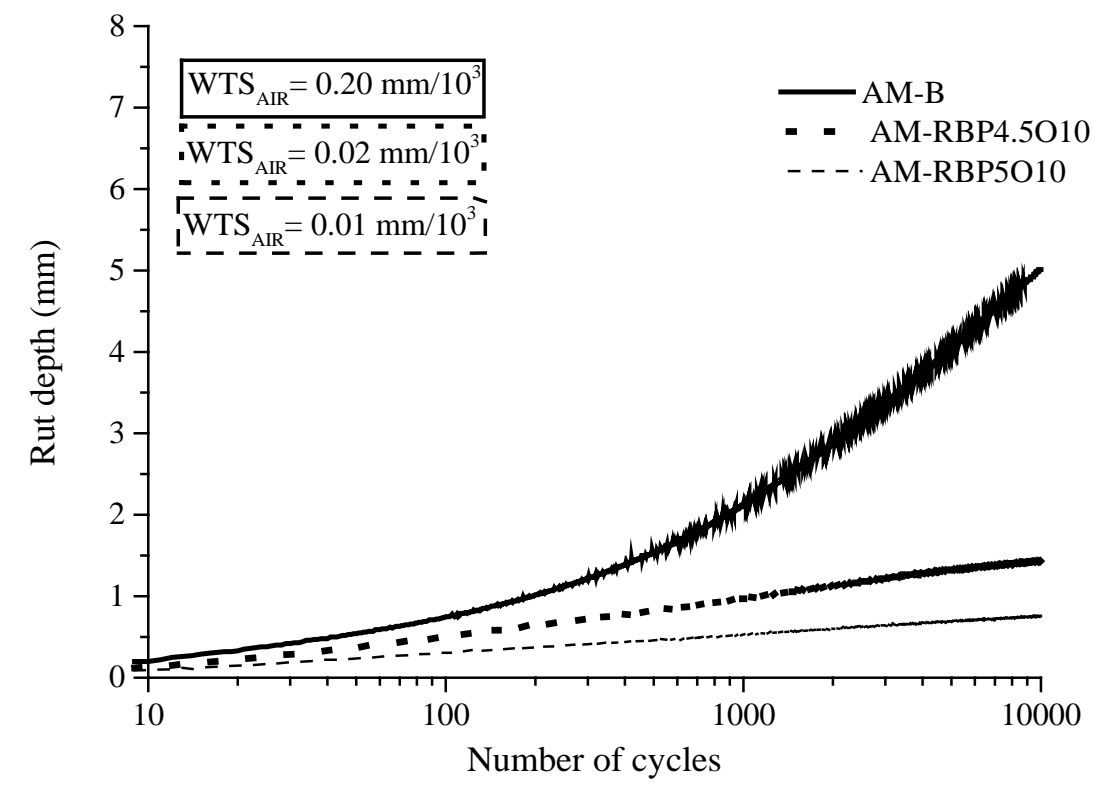

Figure 4. Variation of rut depth with the number of cycles for the studied mixtures. 


\section{CONCLUSIONS}

The present study presents the main results concerning the development of new asphalt mixtures with significant quantities of different waste materials (RAP, motor oil and HDPE), which is expected to have a performance similar or higher than that of a conventional mixture. During the initial basic characterization of the binders, the best performance was obtained by the binders modified with $4.5 \%$ to $5.0 \%$ of HDPE and $10 \%$ of waste motor oil. Then, recycled asphalt mixtures produced with $50 \%$ RAP and the selected modified binders presented higher rutting resistance and similar water sensitivity in comparison with a conventional mixture with 35/50 bitumen, despite their higher air voids contents. It was concluded that it is possible to give a new life to different waste materials (RAP, motor oil, HDPE) in new asphalt mixtures, greatly reducing in $65 \%$ the amount of virgin bitumen used. Thus, these new asphalt mixtures with waste modified binders showed an environmental and economic way to reuse waste materials.

\section{ACKNOWLEDGMENTS}

The authors gratefully acknowledge the funding support of this work, namely the ERDF funds through the Operational Competitiveness Program - COMPETE and the National funds by FCT - Portuguese Foundation for Science and Technology in the scope of PLASTIROADS Project FCOMP-01-0124-FEDER-020335 (PTDC/ECM/119179/2010) and the EU/FSE funds through the POPH/QREN Program in the scope of a FCT Ph.D. grant (SFRH/BD98379/2013).

\section{REFERENCES}

Al-Hadidy, A. I. \& Yi-Qiu, T. (2009) Effect of polyethylene on life of flexible pavements. Construction and Building Materials, 23, 1456-1464.

Casey, D., Mcnally, C., Gibney, A. \& Gilchrist, M. D. (2008) Development of a recycled polymer modified binder for use in stone mastic asphalt. Resources, Conservation and Recycling, 52, 11671174.

Costa, L. M. B., Silva, H. M. R. D., Oliveira, J. R. M. \& Fernandes, S. R. M. (2013) Incorporation of waste plastic in asphalt binders to improve their performance in the pavement. International Journal of Pavement Research and Technology, 6, 457-464.

Dony, A., Colin, J., Bruneau, D., Drouadaine, I. \& Navaro, J. (2013) Reclaimed asphalt concretes with high recycling rates: Changes in reclaimed binder properties according to rejuvenating agent. Construction and Building Materials, 41, 175-181.

Eapa (2011) Asphalt in Figures 2011. Brussels, Belgium, European Asphalt Pavement Association.

Eapa (2012) Asphalt in Figures 2012. Brussels, Belgium, European Asphalt Pavement Association.

Inir (2012) Construção e Reabilitação de pavimentos - Reciclagem de Pavimentos. Instituto de InfraEstruturas Rodoviárias IP.

Karlsson, R. \& Isacsson, U. (2006) Material-Related Aspects of Asphalt Recycling-State-of-the-Art. Journal of Materials in Civil Engineering, 18, 81-92.

Lesueur, D. (2009) The colloidal structure of bitumen: Consequences on the rheology and on the mechanisms of bitumen modification. Advances in Colloid and Interface Science, 145, 42-82.

Palha, D., Fonseca, P., Abreu, L., Silva, H. \& Oliveira, J. (2013) Solutions to improve the recycling rate and quality of plant produced hot mix asphalt. WASTES: Solutions, Treatments and Opportunities. Braga, Portugal.

Reyes-Ortiz, O., Berardinelli, E., Alvarez, A. E., Carvajal-Muñoz, J. S. \& Fuentes, L. G. (2012) Evaluation of Hot Mix Asphalt Mixtures with Replacement of Aggregates by Reclaimed Asphalt Pavement (RAP) Material. Procedia - Social and Behavioral Sciences, 53, 379-388.

Sengoz, B. \& Oylumluoglu, J. (2013) Utilization of recycled asphalt concrete with different warm mix asphalt additives prepared with different penetration grades bitumen. Construction and Building Materials, 45, 173-183.

Silva, H. M. R. D., Oliveira, J. R. M. \& Jesus, C. M. G. (2012) Are totally recycled hot mix asphalts a sustainable alternative for road paving? Resources, Conservation and Recycling, 60, 38-48.

Vislavičius, K. \& Sivilevičius, H. (2013) Effect of reclaimed asphalt pavement gradation variation on the homogeneity of recycled hot-mix asphalt. Archives of Civil and Mechanical Engineering, 13, 345-353. 